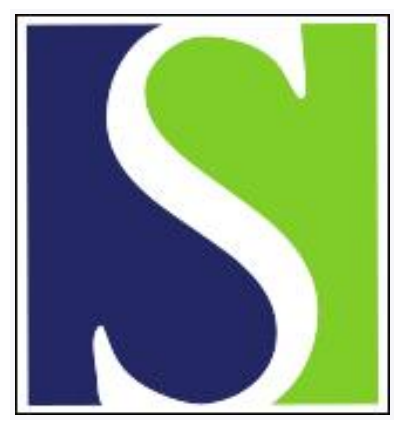

Scand J Work Environ Health 2010;36(6):473-483

https://doi.org/10.5271/sjweh.2986

Published online: 23 Apr 2010, Issue date: Nov 2010

Return to work following disabling occupational injury facilitators of employment continuation

by Young AE

Affiliation: Hopkinton, MA, United States. mandae.young@libertymutual.com

Refers to the following texts of the Journal: $2005 ; 31(5): 367-374$

2008;34(6):430-437 2009;35(4):261-281

The following articles refer to this text: $2010 ; 36(6): 515-516$;

2011;37(2):81-84; 2011;37(6):481-493; 2012;38(2):89-91;

2012;38(5):456-466; 2013;39(5):477-485

Key terms: disablement; employment continuation; injury; long-term sickness absence; occupational injury; rehabilitation; return to work; return-to-work; sickness absence; vocational rehabilitation

This article in PubMed: www.ncbi.nlm.nih.gov/pubmed/20414630

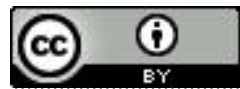




\title{
Return to work following disabling occupational injury - facilitators of employment continuation
}

\author{
by Amanda E Young, PhD ${ }^{1}$
}

\begin{abstract}
Young AE. Return to work following disabling occupational injury - facilitators of employment continuation. Scand J Work Environ Health. 2010;36(6):473-483.

Objective Return to work following occupational injury is an important rehabilitation milestone; however, it does not mark the end of the return-to-work process. Following a return to the workplace, workers can experience difficulties that compromise their rehabilitation gains. Although there has been investigation of factors related to a return to the workplace, little attention has been paid to understanding what facilitates continued return-to-work success as this paper aims to do.
\end{abstract}

Methods This study used data gathered during one-on-one telephone interviews with 146 people who experienced a work-related injury that resulted in their being unable to return to their pre-injury job, but who returned to work following an extended period of absence and the receipt of vocational services.

Results Numerous return-to-work facilitators were reported, including features of the workers' environmental and personal contexts, as well as body function, activities, and participation. Influences that stood out included a perception that the work was appropriate, supportive workplace relationships, and a sense of satisfaction/ achievement associated with being at work.

Conclusions The findings support the contention that initiatives aimed at improving return-to-work outcomes can go beyond the removal of barriers to include interventions to circumvent difficulties before they are encountered. Together with providing ideas for interventions, the study's findings offer an insight into research and theoretical development that might be undertaken to further the understanding of the return-to-work process and the factors that impact upon it.

Key terms disablement; long-term sickness absence; return-to-work; vocational rehabilitation.

With the realization that return-to-work outcomes are only loosely associated with the resolution of symptoms has come research aiming to discover what other factors play a key role in determining outcome. While a number of factors have been found to relate to return to work and biopsychosocial models have been developed, many of the factors found to relate to inferior outcomes are not modifiable, leaving us with the ability to identify a person at risk, but often with little understanding of how to intervene so that the individual can achieve a betterthan-predicted outcome.

Perhaps in response to this, a relatively recent development within the field of return to work has been research that has sought to identify return-to-work barriers, with the rationale being that if we know what problems people are likely to encounter ahead of time, we might be more able to help them avoid them (1).
Along similar lines, it can also be argued that learning from the positive experiences of others will likely help to develop plans that will hold up to predictable stresses and strains.

Thus far, research in this vein has tended to focus on barriers to (2-6) and/or facilitators of (7-10) a return to the workplace. Although this is an important milestone in the return-to-work process, it is only a step toward the achievement of a safe and sustainable employment outcome. Conceptualized as a developmental process, return to work has four phases: (i) off work, (ii) work re-entry, (iii) maintenance, and (iv) advancement (11). While a return to the workplace denotes the end of the off-work phase, the opportunity for the return to work to be compromised has the potential to continue well beyond that event. Although there are numerous supports and services aimed at helping injured workers to go back to work,

1 Center for Disability Research, Liberty Mutual Research Institute for Safety, Hopkinton, Massachusetts, United States.

Correspondence to: Dr AE Young, 71 Frankland Rd, Hopkinton, MA, United States. [E-mail: amandae.young@libertymutual.com] 
once back at the workplace, this support often wanes and the worker can struggle. If the return to the workplace cannot be maintained, the affected individual's return to work often becomes increasingly complicated and has the potential to be terminally compromised. As such, efforts to improve our understanding of factors related to the later phases of the return-to-work process (ie, re-entry, maintenance, and advancement) are justified.

To date there has been little investigation of what influences work continuation after a return to the workplace has occurred. One example is a study of people with spinal cord injury $(\mathrm{N}=20)$ that looked at factors respondents felt facilitated their post-injury employment participation (12). Identified facilitators related to employment maintenance included: flexibility of hours and duties, employer attitude and active facilitation of successful re-employment, bonds between the worker and coworkers, and support from others while regaining functional abilities. Other data providing insight comes from a 10-year follow up of a supported employment program. People who participated in the program reported facilitators including: being able to work reduced hours, on-thejob training, support at the workplace, "having someone help you get along better with the people at work," having someone to talk to about work stress, transport assistance, and "having a trial period to see if you can cope with the work" (13). From the broader return-to-work literature, research suggests that transportation/mobility independence (14-16), good social support for return to work (17), as well as workplace factors - including good supervisor interactions (18) and flexibility of working conditions $(19,20)$ - also have the potential to facilitate the maintenance of employment gains.

This manuscript reports on results from a larger study investigating return-to-work experiences following the receipt of vocational services. Earlier reports have described participant's prevocational rehabilitation return-to-work experiences (21). This report focuses on the part of the project that aimed to develop further an understanding of what facilitates continued returnto-work success following the receipt of vocational services and explore the idea that different influences are important during the various phases of the return-towork process. With this information, we will be better placed to make recommendations regarding initiatives that will efficiently and effectively facilitate the achievement of return-to-work goals.

\section{Methods}

\section{Design and procedure}

While a qualitative approach was considered appropriate for the exploration of participants' return-to-work experiences, in order to address the second part of the aim (ie, an exploration of the idea that different influences are important during different phases of the return-to-work process), the intention was to test for between-group differences and answer questions relating to experience commonality. Given that this could not be achieved using a purely qualitative approach, a design was chosen that involved the blending of qualitative and quantitative data collection and analytical techniques and, consistent with mixed-method procedures (22), a sample was drawn that was larger than typically used when conducting purely qualitative investigations. Although there was a desire to determine if certain influences were important during different phases of the return-to-work process, no attempt was made to draw a minimum sample from any of the subgroups (ie, off work, re-entry, maintenance, advancement). Rather, a consecutive sampling methodology was employed whereby an attempt was made to recruit all people with state-approved returnto-work plans having a return-to-work date on or after the sampling commencement date of 1 January 2003. The intention was to keep sampling until the desired study size $(\mathrm{N}=150)$ was obtained. This occurred in September 2006. While there was no attempt to obtain a minimum sample for any of the subgroups, the decision to continue sampling until 150 people had been recruited was made after a sense of the proportion of people maintaining and not maintaining employment had been gained (ie, when sampling was complete there was the understanding that there should have been around 20 people in the off-work group).

To obtain the desired sample size, 549 invitations to participate in the research were sent out via written invitation, with enclosed and pre-paid response forms. If the invitee did not respond to the invitation within two weeks, attempts were made to reach the individual by phone. In 129 cases (24\%) the provided contact information (mailing address, phone number, or a combination of both) was no longer valid. In an additional two cases, the invitee was reached, but they were unable to be interviewed due to language barriers. An additional five people were not interviewed because they had not returned to work. Of those thought to be eligible and with valid contact information ( $\mathrm{N}=413), 127(30 \%)$ could not be reached despite numerous attempts (minimum of 10 follow-up calls) and 140 (34\%) declined to take part in the study. The remaining 146 people were interviewed. Application of the American Association for Public Opinion Research (AAPOR) standard definitions and allowing for ineligible non-contracts (23) resulted in a calculated response rate (RR3) of $40 \%$. Using the number of eligible respondents successfully contacted as the denominator, the cooperation rate (23) was calculated to be $51 \%$. 
Data were gathered via one-on-one telephone interviews. A concurrent-nested strategy (24) was adopted such that responses to closed-ended questioning led to further open-ended questioning. As such, open-ended questions were interspersed throughout the questionnaire. When collecting the data, the interviewer used a computer-assisted semi-structured proforma. This was pilot tested with experts in the subject area and revised as required. The interview began with demographic and injury questions. After these, questioning turned to postinjury return-to-work experiences and an exploration of what participants thought had helped them continue working. Depending on whether the participant was employed at the time of interview, the opening question specific to facilitation was asked in one of two ways. For those not employed, the question was: "Was there anything that you found helped you stay at work even though it was difficult?" For those employed, the question was: "Is there anything that you have found that is particularly helping you stay at work?"

Interviewers were instructed to follow up participant's comments in a conversational manner (eg, "Can you tell me a bit more about that?") and summarize responses as a way of checking that they had understood and had accurately recorded the participant's thoughts (eg, "So, if I have this right, you would say that the support of your co-workers helped you to stay at work even though it was difficult. Is that right?"). The summary was entered into the computer and an audio recording was made of the entire interview. In addition, interviewers took handwritten field notes to supplement the summarized material and prompt them to follow up on pertinent material. Each interview took about an hour to complete.

Four interviewers were involved in the data collection process. All were female, university-educated and had received in-house training in the conduct of semi-structured interviews from the lead researcher, who had formal training on the topic. Interviewers were unknown to the participants until the time they were approached to schedule an interview. The aims of the project were detailed in the letter of invitation and informed consent was obtained prior to the commencement of interviewing. Participants were also informed that the project was a joint initiative conducted by an area university and an industry-funded research institute. This information, together with a statement indicating that participation would in no way influence their workers' compensation claim, was provided to participants at the time of recruitment. While data regarding the reasons behind why people chose not to participate in the research was not systematically collected, there was no reported instance of refusal because an insurance company was involved. At no time were participants asked to identify their insurer. Based on the insurer's market share within the study catchment area, it is anticipated that only a relatively small proportion (less than 10\%) of the people invited to participate in the research would have received their compensation benefits from the insurer funding the research.

\section{Participants}

All participants were unable to return to their pre-injury job and had accepted workers' compensation claims, state-approved return-to-work plans, received vocational services within the Massachusetts workers' compensation system, and subsequently found a position of employment. Such individuals represent approximately $30 \%$ of those determined by the Office of Education and Vocational Rehabilitation to be suitable for services and referred to insurers for vocational rehabilitation and about $50 \%$ of all those with approved return-to-work plans (25). The vocational services provided to the study population include assistance to develop a plan for employment that includes a review of goals, career interests, work history, educational background, labor market research and trial-work experiences. In addition, assistance is provided with the preparation of resumes/ curriculum vitae, job seeking training skills, job hunting, and interview training skills. Post-placement assistance is also provided. Services are provided under a hierarchy such that if the worker cannot return to the same job, then an effort will be made to modify the job so that they can return to the same employer. If that is unsuccessful, an effort is made to find a different job with the same employer. If that is not possible, an effort is made to find a different job with a different employer. Finally, if that does not eventuate, retraining may be undertaken. [Note: More detail regarding vocational rehabilitation service provision can be found at the official website of the Commonwealth of Massachusetts: www.mass.gov.]

Of the study participants, $38 \%$ were female. The average age at injury was 39.7 years [standard deviation (SD) 8.3] and 43.9 years (SD 8.3) at interview. In 78\% of cases the respondent's medical condition was the result of a trauma. At the time of injury, $5 \%$ had not completed high school, $43 \%$ were high school graduates and $51 \%$ had undertaken some type of further education. Threequarters of participants had undertaken some post-injury training. Prior to their injury, the majority of participants had worked in the service industry (34\%). Construction, transportation and utilities, and retail trade workers were also well represented (17\%, 15\% and 13\%, respectively). Participants' pre-injury occupations covered the full range, but most could be categorized as being in associate professional and technical (23\%) and elementary occupations $(23 \%)$. The average time between injury and the commencement of the participant's post-vocational services return to work was 37.63 months (SD 17.72). The average time between the commencement of the return to work and interview was 1.05 years (SD 0.84). 


\section{Data interpretation and presentation}

Once collection was complete, data were exported from the computer-assisted interviewing software to various data management programs. Pre-coded data were sent directly to SPSS version 15 (SPSS Inc, Chicago, IL, USA). Responses to the open-ended questions were exported to Microsoft Word and then later Excel (Microsoft Corp, Redmond WA, USA), and subject to a directed content analysis (26). Assessment of a participant's placement in the return-to-work process was made by the lead researcher. This was rated based on the participant's employment status, time in their current position, their self-assessed performance, and their plans to pursue other work. Those not at work were classified as being off work. Those who had been in their current position for a relatively short period and gave an indication that they were not yet performing to expectation were categorized as being in the re-entry phase. Those who had been in their job for longer periods and reported performing well were categorized as being in the maintenance phase. Those pursuing alternative work were categorized as being in the advancement phase.

Two researchers who had been involved in the data collection process performed the analysis of responses regarding facilitatory influences. The analytical process involved breaking down the participant's responses to meaningful elements (ie, succinct words or phrases that captured an essential meaning). These were then represented on flash/index cards. If an individual gave a response involving more that one element, multiple cards were made up. For example, if a participant mentioned the support of their healthcare provider and the work being appropriate, this was reflected on two separate cards.

Cards were then sorted and coded using the conceptual framework afforded by the Word Health Organization's International Classification of Functioning, Disability, and Health (ICF) (27). The ICF describes functioning as the interplay of body functions, body structures, activities and participation, and environmental and personal factors and provides a taxonomy that includes component and second-order codes $(28,29)$. Previous researchers conducting qualitative investigations of patients' functional problems have used the ICF, and it has been found to accommodate most patient articulations (30-32). Although the ICF has proven useful, it has been found that some meaning is not captured through application of the coding structure (30). Therefore, while data is presented within the overarching framework and interpreted referencing existing codes, if the application of an existing code resulted in a loss of meaning, a code was not applied. Instead, a descriptive emergent code was chosen and applied. This approach is consistent with ICF-supporting material, which states that the ICF should be considered as a building block and applied according to the needs of the user depending on their creativity and scientific orientation (27).

The coding of data pertaining to facilitatory influences was iterative. Duplicate cards were made where it was felt that more than one element was being mentioned; cards were removed if it was deemed that withinparticipant duplication had occurred. Categorizations were refined throughout the analytical process. Where there was a discrepancy between the coders, this was discussed and resolved through reference to the ICFsupporting materials and, if needed, review of the audio recordings. Following the initial round of coding, the original transcripts were again consulted to ensure that all relevant information had been included.

Once reduced to categorizations, the qualitative data was mixed with the quantitative data and subject to simple uni- and bivariate analyses. Due to the data's lack of parametric properties, $\chi^{2}$ analyses were chosen to test the significance of between-group differences. If the smallest expected cell frequency was $<5$, Fisher's exact test (FET) was applied. Coded responses regarding facilitatory influences were cross-tabulated by the participant's return-towork phase (ie, off work, work re-entry, maintenance, or advancement). When individuals reported facilitators of the same type (eg, orthotics, back brace, and heating pads), these were grouped together (in this case as "products") and recorded as one unit (as opposed to three). As such, each unit (as reported in table 1) represents a person that reported a facilitatory influence of that type, regardless of whether or not he or she mentioned one or more influences of that type. Component level totals (ie, environment, personal, body function, and activities/ participation) detail the number of people reporting an influence that could be categorized as being of that type. The same is true for the sub-component categories "working conditions" and "coping style."

While summaries are useful for revealing group trends, they do not convey a sense of the individual. To provide some context, illustrative examples have been included in the text. Where participant identification numbers have been provided, these include a notation of that individual's phase in the return-to-work process, such that off work $=0$, re-entry $=1$, maintenance $=2$ and advancement=3. As an example "ID31-2" denotes the $31^{\text {st }}$ person invited to participate in the research who was in the maintenance phase at the time of interview.

\section{Results}

Overall, $83 \%$ of participants reported some influence that helped them to stay at work (ie, a facilitator). Comparisons between those off work and those in the other 
Table 1. Participants' self-reported facilitators of employment maintenance classified according to the International Classification of Function, Disability, and Health (ICF) a and cross-tabulated by the return-to-work phase at the time of interview.

\begin{tabular}{|c|c|c|c|c|c|c|c|c|c|c|}
\hline \multirow[t]{2}{*}{ Facilitator $^{b}$} & \multicolumn{2}{|c|}{$\begin{array}{l}\text { Off work } \\
(\mathrm{N}=21)\end{array}$} & \multicolumn{2}{|c|}{$\begin{array}{l}\text { Reentry } \\
(\mathrm{N}=14)\end{array}$} & \multicolumn{2}{|c|}{$\begin{array}{l}\text { Maintenance } \\
\quad(\mathrm{N}=73)\end{array}$} & \multicolumn{2}{|c|}{$\begin{array}{l}\text { Advancement } \\
\quad(\mathrm{N}=38)\end{array}$} & \multicolumn{2}{|c|}{$\begin{array}{c}\text { Total } \\
(\mathrm{N}=146)\end{array}$} \\
\hline & $\begin{array}{l}\text { Facilitatory } \\
\text { influence } \\
\text { (N) }{ }^{c}\end{array}$ & $\%$ & $\begin{array}{l}\text { Facilitatory } \\
\text { influence } \\
\text { (N) }{ }^{c}\end{array}$ & $\%$ & $\begin{array}{l}\text { Facilitatory } \\
\text { influence } \\
\text { (N) c }\end{array}$ & $\%$ & $\begin{array}{l}\text { Facilitatory } \\
\text { influence } \\
\text { (N)c }\end{array}$ & $\%$ & $\begin{array}{l}\text { Facilitatory } \\
\text { influence } \\
(\mathrm{N})^{c}\end{array}$ & $\%$ \\
\hline None & 7 & 33 & 0 & 0 & 14 & 19 & 4 & 11 & 25 & 17 \\
\hline Environmental (e) & 12 & 57 & 10 & 71 & 43 & 59 & 27 & 71 & 92 & 63 \\
\hline Medication (e1101) & 4 & . & 1 & . & 1 & . & 2 & . & 8 & 6 \\
\hline Products (e1151) & 0 & . & 2 & . & 2 & . & 3 & . & 7 & 5 \\
\hline Support (e3) & 1 & . & 1 & . & 2 & . & 1 & . & 5 & 4 \\
\hline Services (e5) & 1 & . & 0 & $\cdot$ & 1 & . & 0 & . & 2 & 1 \\
\hline Economy & 0 & . & 0 & . & 2 & . & 0 & . & 2 & 1 \\
\hline Working conditions (e1, e2, e3 \& e5) & 10 & 48 & 8 & 57 & 34 & 47 & 23 & 61 & 75 & 51 \\
\hline Paycheck/money/benefits & 4 & . & 3 & . & 12 & . & 9 & . & 28 & 19 \\
\hline Work is appropriate & 2 & . & 2 & . & 11 & . & 7 & . & 22 & 15 \\
\hline Supportive coworkers (e325) & 2 & . & 3 & . & 7 & . & 7 & . & 19 & 13 \\
\hline Flexibility of schedule/duties & 2 & . & 1 & . & 7 & . & 3 & . & 13 & 9 \\
\hline Supportive employer/boss (e330) & 1 & . & 1 & . & 5 & . & 3 & . & 10 & 7 \\
\hline Equipment (e151) & 0 & . & 0 & . & 1 & . & 6 & . & 7 & 5 \\
\hline Close to home/convenient & 0 & . & 0 & . & 0 & . & 3 & . & 3 & 2 \\
\hline Part-time/reduced hours & 0 & $\cdot$ & 1 & . & 1 & . & 0 & $\cdot$ & 2 & 1 \\
\hline Personal (p) & 3 & 14 & 5 & 36 & 31 & 43 & 12 & 32 & 51 & 35 \\
\hline Enjoyment of job/job satisfaction & 1 & . & 1 & . & 18 & . & 6 & . & 26 & 18 \\
\hline Want to work/be productive & 3 & . & 0 & . & 3 & . & 2 & . & 8 & 6 \\
\hline Coping style & 0 & 0 & 4 & 29 & 10 & 14 & 3 & 8 & 17 & 12 \\
\hline Attitude/faith/hope & 0 & . & 3 & . & 4 & . & 2 & . & 9 & 6 \\
\hline Knowing limits, working accordingly & 0 & . & 0 & . & 6 & . & 1 & . & 7 & 5 \\
\hline Asking for help when needed & 0 & . & 1 & . & 1 & . & 0 & . & 2 & 1 \\
\hline Skills & 0 & . & 0 & . & 1 & . & 1 & . & 2 & 1 \\
\hline Body function (b) & 0 & 0 & 0 & 0 & 1 & 1 & 1 & 3 & 2 & 1 \\
\hline No pain/fully recovered & 0 & . & 0 & . & 1 & . & 1 & . & 2 & 1 \\
\hline Activities \& Participation (d) & 3 & 14 & 2 & 14 & 12 & 16 & 3 & 8 & 20 & 14 \\
\hline Economic self sufficiency (d870) ${ }^{d}$ & 1 & . & 0 & . & 4 & . & 3 & . & 8 & 6 \\
\hline Exercise (d5701) & 1 & . & 1 & . & 6 & . & 0 & $\cdot$ & 8 & 6 \\
\hline Learning new skills (d198) & 1 & . & 1 & . & 2 & . & 0 & . & 4 & 3 \\
\hline
\end{tabular}

a ICF classification codes are presented within the square brackets following the description of the influencing factors. If no code is listed, no applicable code could be identified.

${ }^{b}$ ICF classification code in parentheses.

c Number of people mentioning facilitatory influence.

${ }^{d}$ This category overlaps with the paycheck/money/benefits category listed above. The rationale for including it separately relates to the stated importance of being able to provide for oneself and/or family.

phases indicated that there were significantly fewer people in the off-work phase that reported facilitatory influences in comparison with those employed (FET $\mathrm{P}<0.05$ ). More detailed analysis indicated a significant difference between those off work and those in the reentry and advancement phases (FET $\mathrm{P}<0.05$ ). Of those reporting being assisted by something $(\mathrm{N}=121), 52 \%$ mentioned only one influence (mean $=1.3$ ); the remaining reported between two and four facilitators $(2=36 \%$, $3=11 \%, 4=1 \%$ ). The mean number of facilitators was not found to relate to return-to-work phase (off-work mean $=1.1$, re-entry mean $=1.5$, maintenance mean $=1.3$, advancement mean=1.4), nor whether or not they were employed at the time of interview (working mean=1.4, not working mean=1.1). Summarized responses crosstabulated by the participant's return-to-work phase are detailed in table 1 . The following is a description of what participants reported, organized within the conceptual framework afforded by the ICF.

\section{Environmental influences}

Of the study participants, $63 \%$ reported that some feature of their physical, social, or attitudinal context had helped them overcome the difficulties they were experiencing. The most commonly reported influences were features of the individual's working conditions, but they also included more general environmental influences, 
including medications (most commonly reported by those in the off-work phase), products (more commonly reported by those working at the time of the interview), services, supportive relationships, and the economy. In all cases, the medications that people mentioned were for pain management. The products that people reported included heat and ice (ID80-1, ID175-1, and ID481-3), transcutaneous electrical nerve stimulation (TENS) units (ID80-1 and ID481-3), orthotics (ID71-2 and ID423-2), and back brace and kneepads (ID277-3).

Five individuals cited the support of others. In some cases, the support was said to have come from family and friends (ID75-1, ID87-1, and ID497-3); for others, it was the support of people assisting the worker in their return to work. Two people, both in the maintenance phase, talked about how their providers had been helpful in that they had encouraged them to take their time and find a job that suited their skills and interests (ID41-2 and ID132-2). Only one person said that healthcare services per se were something that had helped them to stay at work. This person referenced physical therapy and acupuncture (ID275-0). One person indicated that something that he found helpful was "not having to deal with doctors who think you are faking it" (ID334-2). Two individuals indicated that what they hoped would be an improved demand for their services was something that helped them keep going (ID426-2 and ID434-2).

Slightly more than half of the participants $(51 \%)$, spoke about some feature of the individual's employment conditions. Most frequently, this involved money and was true for approximately $20 \%$ of most of the four groups, with a slight deviation for those in the maintenance phase, $16 \%$ of whom said it was important. A factor that was of importance for all groups was that the duties were appropriate. Across all groups, people spoke of the advantage of having duties they knew were within their physical capacity. Embedded within such comments were references to safety and the avoidance of further injury and symptom exacerbation, with examples including: "got more into the programming aspect to eliminate the lifting and more physical aspects" (ID220-0), "won't have to strain myself physically" (ID364-1) "have no lifting requirements and that was a major concern" (ID523-2), "not feeling pain at this job ... not sure could return to [previous job] ... worried about the pain returning if had to lift again" (ID338-3). A trend was noted for those in the later phases, where work that suited the participant's interests and skills was said to be of importance (ID132, ID132-2, ID442-2, and ID392-3). Such comments did not come from people in the off-work and re-entry phases.

The influence of supportive workplace relationships was mentioned by participants in all phases of the return-to-work process. While both employers/ supervisors and coworkers were spoken about, coworker support was mentioned more frequently. People in all phases mentioned the facilitatory impact of supportive coworkers; however, there appeared to be a developmental quality to the way coworkers were referenced. Take for example the case of an individual who was not working at the time of the interview: "The people that I worked with would help with the lifting. They would come over on their own to help a lot, but they would get reprimanded" (ID81-0). Contrast this with a participant, in the re-entry phase, who said she benefited from asking for help from her colleagues when she needed it. "I've got better at asking for help ... hard to do, but it has gotten easier." (ID446-1). Also, this from participants in the maintenance and advancement phases: "The use of the young kids for lifting ... really good team of people ... everybody helps everybody" (ID237-2); "Co-workers help with heavy things ... employer negotiates the work as they go" (ID431-3). As was alluded to above, support from coworkers and supervisors was commonly coupled. This is further supported by the fact that half of the people talking about the influence of the support of their employer/supervisor also referenced their coworkers.

Thirteen participants mentioned the benefits of flexible working conditions. Statements coded into this category included those relating to flexibility of: hours (eg, ID118-1, ID393-3, ID428-2, and ID537-3), duties (ID59-2 and ID375-3), breaks (ID314-0, ID3753, ID416-2, and ID532-2), pace (ID75-0, ID105-2, and ID509-2), and physical working conditions (ID467-3). Among those who spoke about flexibility, control of their working conditions and ability to respond to their symptomatology appeared to be key to their success: "figuring out what works best ... knowing what will push me over the limit ... breaking up the day into manageable tasks that will not stress my wrists ... limiting number of hours of repetitive movement" (ID59-2), "being able to get up and do something else if I am experiencing symptoms" (ID375-3), "flexibility to get up and move around and have breaks when I need to" (ID532-3), "being able to put my leg up on the cabinet under the register ... being able to sit on a stool when I need to" (ID467-3).

Seven of the participants spoke of the benefits of workplace equipment. In most cases, the equipment was not specifically designed for a person with activity limitations and included: items with push-button technology [eg, hydraulic lift (ID277-3) and an electric hospital bed (ID435-3)], ergonomic workstation (ID515-3) and seating (ID481-3 and ID515-3). All those who spoke of the influence of equipment were in the maintenance and advancement phases. Convenience - as in a convenient commute (ID125-3 and ID286-3) and fitting in with 
the family schedule (ID537-3) - was only mentioned by those in the advancement phase. The benefit of working reduced hours was spoken about by only two individuals: one in the re-entry phase who was building her capacity (ID74-1) and one in the maintenance phase who was working part-time and who said she would leave if her symptoms worsened and she was in pain all the time (ID86-2).

\section{Personal factors}

Although the ICF currently classifies only environmental influences as having the potential to exert facilitatory effects, not all participant responses could be classed as environmental in nature. Facilitators that could be classified (according to the ICF guidelines) as being part of the participant's personal context were mentioned by $35 \%$ of the sample. The most commonly mentioned factor was job satisfaction, which was most frequently reported by those in the maintenance phase. Interestingly, an appreciation of being at work (as opposed to off work) was also mentioned with relative frequency, but most commonly done so by those not working at the time of interview: "wanted to keep busy" (ID20-0), "not one to just sit there ... love to work" (ID305-0), "the job was good for me, I got to do a lot of different things" (ID439-0). Comments made by those in the maintenance and advancement phases included: "I love people, have to be with people ... love working ... did not like the isolation when out of work" (ID371-2), "work is like physical therapy ... helped me to get fingers moving" (ID126-2), "feeling that you are doing something again" (ID126-3), and "glad to be back at work" (ID184-3).

Another group of facilitators, which can be classed as relating to the individual's coping style, also played a role. Inspection of the comments made by those in the later phases indicates a difference in the techniques used. Those in the re-entry phase tended to talk more about attitude and determination (ID50-1, ID213-1, and ID391-1), whereas those in the maintenance phase talked more about knowing their limits and working accordingly, again suggesting a developmental nature to work re-entry and what is needed at different times throughout the return-to-work process. Another personal characteristic was asking for help when it was needed. Although this was spoken about by just two individuals, it is worthy of note given the stated importance of coworkers. Interestingly, even though these people indicated that they benefited from the assistance of others, this was not always easily asked, as was the case for ID446 who was in the re-entry phase. A sense of confidence can be noted in responses stating that their own personal skill set was something that kept them on the job (ID332-2 and ID393-3).

\section{Physical body function, actions and participation}

While only two people (ID338-3 and ID512-2) indicated that their physical/pain-free status was something that helped them to stay at work, a number of people indicated that what they did to maintain their body function was important. This was true for people in the first three return-to-work phases, but most commonly among those in the maintenance phase. Again, there appeared to be a developmental nature with regards to exercise and its benefits. For illustration, take these examples from individuals in the first three return-to-work phases: "getting up quite frequently and taking a walk" (ID314-0), "stretching everyday" (ID175-1), and "exercise has been very important in motivating me to work hard and be a better employee ... more alert ... became 'semi-retired' not working" (ID483-2). Others within the maintenance phase talked about using their lunch break to take walks (ID228-2), the importance of their regular exercise regime (ID423-2 and ID456-2) and the benefit of "keeping active, keeping going" (ID525-2).

Although captured to some extent as the facilitatory impact of earning money and having healthcare benefits, a number of individual's went further in their explanation. In eight cases, people indicated that beyond receiving a paycheck, what they were able to do with it (in terms of being able to pay their bills and provide for their family) was something that helped them to stay at work. The four people who talked about the facilitatory influence of learning new skills were all in the first three phases of the return-to-work process. In three of these cases, people had moved into jobs that required further training: “... learning something I like. [Apprenticeship type] was not my first choice, but I am getting to like it more as I get to know more about it" (ID50-1), "lectures are great ... continually improving knowledge" (ID293-2), "continuing education is a true blessing" (ID47-2).

\section{Discussion}

The fact that $83 \%$ of the sample reported that some influence had helped them to stay at work indicates that the vast majority of people who return to work following disabling injury are accessing resources that facilitate the maintenance of their rehabilitation gains. Consistent with the ICF conceptualization (27), environmental contexts were reported to exert a positive influence on the individual's performance. The most commonly reported environmental facilitator was the resource rewards associated with working. Although a recent review of cohort studies investigating prognostic factors has indicated no evidence for the role of income in disability duration and 
return to work (33), as is likely the case for many of us, respondents indicated that their paycheck and insurance benefits helped them to stay at work. However, while this may well be the case, the extent to which such rewards can be manipulated to improve return-to-work outcomes is largely dependant on economic conditions and as such, these factors are unlikely to prove a useful focus for intervention.

While a number of the factors that people talked about are also those that would likely help the typical individual stay at work (eg, paycheck, work fitting in with other commitments, and job satisfaction), some influences appeared more important than might normally be the case. One such feature was an emphasis on the work being appropriate, with safety being an important index thereof. It would appear that identification of appropriate work is important not only for timely return to work (34), but also for work maintenance. Related to work appropriateness, and consistent with earlier studies $(8,19,20,35)$, were the reported benefits of a workplace/supervisor that allowed flexibility for task variation, breaks, and autonomous decision-making. These findings support the suggestion that a working relationship that allows "decision latitude", that is an employee's ability to make decisions related to the way he/she work, can help employees devise coping strategies than can mitigate the effects of workplace stressors (36) and support return to work following long-term sickness absence (37). Similarly, findings are in line with the idea that a freedom to develop different ways of working in order to meet production targets (referred to as "margin of maneuver") can help rehabilitating workers get the job done (38). As such, the findings support the suggestion that application of the margin of maneuver concept to work rehabilitation can help those involved in return-to-work planning to evaluate more systematically indicators pertinent to work performance and help integrate a person-environment model that facilitates the meeting of production targets without compromising worker health (38).

The results of this study are consistent with earlier work that has demonstrated that supervisors can have an impact on return to work $(18,39)$, but also highlight the important role of coworkers. Although coworkers have been previously identified as providing assistance that helped in the transition to employment, this was considered secondary to the support of family, friends and pre-injury employers (12). In this study, coworkers were more consistently identified than any other group. The assistance provided was both practical and psychosocial in nature, suggesting that workplace relationships and practical support contributed to helping the worker stay at work. In the context of earlier research indicating that a lack of collegial support was a barrier to work re-entry following a stroke (8) and a cohort study that has demonstrated that coworkers support was related to productivity for those with inflammatory joint conditions (35), workplace relationships appear to be an important feature of the environmental landscape and one that could benefit from input regarding how to best demonstrate and provide coworker support.

Consistent with previous research, other people, including healthcare providers, family, and lawyers were also reported to play an influential role. These people, collectively referred to as "return-to-work stakeholders", have been argued to have the potential for differing return-to-work-related interests and motivations (40). As such, it is understandable that there were instances where the assistance given was not enthusiastically endorsed and conflict and ill feelings resulted. The current findings are in support of the contention that when planning work reentry, it is important that stakeholders are engaged (39), be advised to make an effort to ensure that communication is clear and explicit (41), and are coordinated in their efforts $(10,42)$. Further, these findings suggest that there is a need for a shared and ongoing commitment to the return-to-work goal and related plan. With such, those involved will be better placed to provide the returning worker with the needed assistance and support.

The workplace equipment that people referenced tended to be relatively simple and likely to be found in most modern workplaces. This finding may prove reassuring to return-to-work stakeholders in that it demonstrates that modifications to accommodate the limitations of an injured worker do not need to be extensive or expensive. This is also true for the treatment products people spoke about using. Of some concern was that people who indicated that medication had been instrumental were more frequently not working at the time of interview than those who spoke about other facilitatory influences. This finding is in line with earlier research that indicates that passive forms of coping tend to be associated with inferior return-to-work outcomes (43) and suggests that a reliance on pain medication, as opposed to taking a more active coping approach, is not something that is associated with long-term success.

While the ICF conceptualized only environmental factors as facilitators (28), participants' responses indicated that there were influences beyond their environment that helped them to manage and overcome the difficulties they experienced. These included personal characteristics and a variety of other experiential influences associated with undertaking tasks and actions. The findings also point to physiological body function as a facilitator of the maintenance of rehabilitation gains and suggest an opportunity for proactive intervention. Together with a desire to be working/productive, work enjoyment, and/or personal satisfaction was an important influence for people in all return-to-work phases, but particularly so for those in the later stages. This 
finding stresses the importance of finding work that not only is within the individual's physical abilities, but also fulfills the worker's emotional and intellectual needs. This finding is consistent with past investigations of durable employment following disabling injury (44) and supports the position of Holland who emphasizes the need to match the physical demands of the job with interests and personality type (45).

The influences people spoke about varied greatly; however, this should not be interpreted to suggest that participants were not facilitated by similar influences as the way the interview question was phrased placed emphasis on what the participant thought had particularly helped them stay at work. As such, study findings reflect the broad scope of factors that can play a role in facilitating employment maintenance, but do not portray what happens at an individual level. Further and preferably prospective research would be needed to achieve this level of understanding.

While transportation has previously been identified as an important facilitator of return to work (14-16), it was not a standout feature for those taking part in this research. An explanation for this might be that, once appropriate transportation had been established and a return to the workplace had been achieved, transportation in no longer an important facilitatory force. This is not to say that a disruption to established transportation patterns might not constitute a barrier to employment continuation; rather, that once the issue of transportation has been successfully addressed, it is not something that appears to require further development. As such transportation may be a perceived as facilitator of the transition from the off-work to re-entry phase, but not necessarily facilitatory of on-going success.

Methodological considerations concerning loss to recall have been discussed earlier (21). Specific to the data presented in this manuscript, it is likely that when thinking about what helped them stay working, participants referenced their most recent experience; as such it is likely that there is an underreporting on facilitatory influences important during earlier phases of the individual's return to work. Data presented in this paper were gathered with the use of a semi-structured interview - a format that is valuable for exploring experiences and perceptions and developing rapport, but also one where the interviewer is involved in the production of data. While interviewers were instructed to avoid dispensing advice, expressing judgment, or providing reinforcement, the quality of the personal interaction likely influenced the participants' responses. Given the exploratory nature of this research, a level of interviewer involvement was deemed acceptable; however, future researchers aiming to test specific hypotheses and draw generalizable conclusions would be advised to employ a more structured approach. The fact that the research was funded by an insurance provider was not an interview topic, but based on the perceptions of the research team, members of which had also conducted interviews while working for academic institutions and government departments, it did not appear to be a factor of importance to the interviewees. The extent to which results generalize to those who do not go on to receive vocational services is unclear. However, given that research has found that more than half of people with compensated occupational injuries have ongoing limitations (46), it is likely that the problems encountered are not unique to the study population. While it is likely that others encounter similar problems, the current sample is of particular interest because they successfully negotiated the complicated return-to-work process, managing to find employment, and - for the most part - staying employed. This highlights the potential for differences between the experiences of the study participants and other injured workers; however, as exemplars, the current sample has the potential to teach us much about what facilitates success.

Although study findings provide insight, the ability to draw firm conclusions about the causal nature of the observed relationships is limited due to the study's crosssectional design. For example, while a proactive style was associated with the advancement phase, this may be a function of the experience of achievement "teaching" the worker to be more proactive. This has implications for those developing interventions based on study findings in that, if identified facilitators are not causally related, interventions aimed at improving access to facilitatory influences will not produce the desired effect. Further research employing a longitudinal design is needed to confirm the importance of the facilitators identified. While the sample was relatively large, the small numbers in each of the return-to-work phase groups, and the diversity in the facilitators reported, meant that the capacity for the testing of phase-specific facilitators was limited. However, trends do suggest that influences can be important at different times and that there is a developmental nature to the facilitatory influences such that they are more highly evolved at later phases of the return-to-work process. This is consistent with earlier research suggesting that there are phase-specific predictors of work disability (47) and implies that additional investigations along these lines would provide more specific information regarding what would be beneficial to workers in the various phases of the return-to-work process. Future work aiming to test for between-group differences might benefit from a staged recruitment procedure; when the desired sample for the first of the groups (eg, maintenance) has been achieved, stage two begins and only those in the underrepresented group (eg, off work, re-entry, and advancement) would be interviewed. This process of targeted recruitment would continue until the desired sample size for the final group 
has been reached. Along similar lines, research investigating facilitators or other phases of the return to work process (eg, from maintenance to advancement) has the potential to improve the long-term outcomes of injured workers.

\section{Concluding remarks}

The reported facilitatory influences were numerous and varied. Although many were contextual, they also included influences that may not have previously been thought of as facilitators. These findings support the suggestion that facilitatory factors are more than just the opposites of barriers and can include actions to be taken to overcome difficulties (48). As such, the current results add support to the argument that initiatives aimed at improving return-to-work outcomes can go beyond the removal of obstacles to include interventions to circumvent difficulties before they are encountered. The findings suggest that those involved in the return-to-work process have the potential to intervene within contextual environments to improve work-disability outcomes. At this stage, it would appear that ongoing good health and workplace support are the two factors that have the greatest potential to facilitate long-term return-to-work success; however, further longitudinal research is required to confirm and determine the extent of this potential.

\section{Acknowledgement}

Liberty Mutual provided financial support for this research.

\section{References}

1. Bennion SK. Overcoming barriers for a successful return to work. Prof Case Manag. 2008;13(4):241-3.

2. Schneider JC, Bassi S, Ryan CM. Barriers impacting employment after burn injury. J Burn Care Res. 2009;30(2):294-300.

3. Esselman PC, Askay SW, Carrougher GJ, Lezotte DC, Holavanahalli RK, Magyar-Russell G, et al. Barriers to return to work after burn injuries. Arch Phys Med Rehabil. 2007;88(12 suppl 2):S50-6.

4. MacEachen E, Kosny A, Ferrier S. Unexpected barriers in return to work: lessons learned from injured worker peer support groups. Work. 2007;29(2):155-64.

5. Magnussen L, Nilsen S, Raheim M. Barriers against returning to work - as perceived by disability pensioners with back pain: a focus group based qualitative study. Disabil Rehabil. 2007;29(3):191-7.
6. Patel S, Greasley K, Watson PJ. Barriers to rehabilitation and return to work for unemployed chronic pain patients: a qualitative study. Eur J Pain. 2007;11(8):831-40.

7. Cote P, Clarke J, Deguire S, Frank JW, Yassi A. Chiropractors and return-to-work: the experiences of three Canadian focus groups. J Manipulative Physiol Ther. 2001;24(5):309-16.

8. Alaszewski A, Alaszewski H, Potter J, Penhale B. Working after a stroke: survivors' experiences and perceptions of barriers to and facilitators of the return to paid employment. Disabil Rehabil. 2007;29(24):1858-69.

9. Baril R, Clarke J, Friesen M, Stock S, Cole D. Management of return-to-work programs for workers with musculoskeletal disorders: a qualitative study in three Canadian provinces. Soc Sci Med. 2003;57(11):2101-14.

10. Friesen MN, Yassi A, Cooper J. Return-to-work: the importance of human interactions and organizational structures. Work. 2001;17(1):11-22.

11. Young AE, Roessler RT, Wasiak R, McPherson KM, van Poppel MN, Anema JR. A developmental conceptualization of return to work. J Occup Rehabil. 2005;15(4):557-68.

12. Murphy GC, Young AE. Employer-based facilitators to work following disabling injury. Int $\mathrm{J}$ Disabil Manage. 2006;1(4):125-34.

13. Salyers MP, Becker DR, Drake RE, Torrey WC, Wyzik PF. A ten-year follow-up of a supported employment program. Psychiatr Serv. 2004;55(3):302-8.

14. Britell C. Why aren't they working? J Am Paraplegia Soc. 1991;14(1):1-2.

15. Capozzi DM, Cannon DM. Transportation accessibility. In: Dell Orto AE, Marinelli RP, editors. Encyclopedia of disability and rehabilitation. New York (NY): Simon and Schuster Macmillan; 1995. p 731-8.

16. Kiernan W, Conley R. Issues, outcomes and barriers to employment for adults with developmental disabilities. J Rehabil Adm. 1989;13:5-11.

17. Murphy GC, Young AE. Contradictory effects of social support in rehabilitation. Aust J Prim Health Interchange. 1998;4(1):18-27.

18. Shaw WS, Robertson MM, McLellan RK, Verma S, Pransky G. A controlled case study of supervisor training to optimize response to injury in the food processing industry. Work. 2006;26(2):107-14.

19. Stikeleather J. An older worker's decision to "push or protect self" following a work-related injury. Work. 2004;22(2):139-44.

20. Corbet B. Options: spinal cord injury and the future. Newton (MA): National Spinal Cord Injury Association; 1980.

21. Young AE. Return-to-work experiences: prior to receiving vocational services. Disabil Rehabil. 2009;31(24):2013-22.

22. Bryman A. Social research methods. New York (NY): Oxford; 2006.

23. American Association for Public Opinion Research (AAPOR). Response rates - an overview. Lenexa (KS): AAPOR; 2006.

24. Bowling A, Ebrahim S. Handbook of health research methods: investigation, measurement and analysis. Maidenhead (United Kingdom): Maidenhead Open University Press; 2005. 
25. Vercillo A. Job retention success for individuals receiving vocational services after a work-related injury. Boston (MA): Boston University; 2008.

26. Hsieh H-F, Shannon SE. Three approaches to qualitative content analysis. Qual Health Res. 2005;15:1277-88

27. World Health Organization (WHO). Towards a common language for functioning, disability and health. Geneva: WHO; 2002 .

28. World Health Organization (WHO). International classification of functioning disability and health. Geneva: WHO; 2001.

29. World Health Organization (WHO). ICF cheacklist. Geneva: WHO; 2003.

30. Stamm T, Machold K. The International Classification of Functioning, Disability and Health in practice in rheumatological care and research. Curr Opin Rheumatol. 2007;19(2):184-9.

31. Duggan CH, Albright KJ, Lequerica A. Using the ICF to code and analyse women's disability narratives. Disabil Rehabil. 2008;30(12-13):978-90.

32. Sundar V, Daumen ME, Conley DJ, Stone JH. The use of ICF codes for information retrieval in rehabilitation research: an empirical study. Disabil Rehabil. 2008;30(12-13):955-62.

33. Detaille SI, Heerkens YF, Engels JA, van der Gulden JW, van Dijk FJ. Common prognostic factors of work disability among employees with a chronic somatic disease: a systematic review of cohort studies [review]. Scand J Work Environ Health. 2009;35(4):261-81.

34. Schweigert MK, McNeil D, Doupe L. Treating physicians' perceptions of barriers to return to work of their patients in Southern Ontario. Occup Med (Lond). 2004;54(6):425-9.

35. Geuskens GA, Hazes JM, Barendregt PJ, Burdorf A. Predictors of sick leave and reduced productivity at work among persons with early inflammatory joint conditions. Scand J Work Environ Health. 2008;34(6):420-9.

36. Halpern DF. How time-flexible work policies can reduce stress, improve health, and save money. Stress Health. $2005 ; 21: 157-68$.

37. Josephson M, Heijbel B, Voss M, Alfredsson L, Vingard E. Influence of self-reported work conditions and health on full, partial and no return to work after long-term sickness absence. Scand J Work Environ Health. 2008;34(6):430-7.

38. Durand MJ, Vezina N, Baril R, Loisel P, Richard MC, Ngomo $\mathrm{S}$. Margin of manoeuvre indicators in the workplace during the rehabilitation process: a qualitative analysis. J Occup Rehabil. 2009;19(2):194-202.

39. Lotters F, Meerding WJ, Burdorf A. Reduced productivity after sickness absence due to musculoskeletal disorders and its relation to health outcomes. Scand J Work Environ Health. 2005;31(5):367-74.

40. Young AE, Wasiak R, Roessler RT, McPherson KM, Anema JR, van Poppel MN. Return-to-work outcomes following work disability: stakeholder motivations, interests and concerns. J Occup Rehabil. 2005;15(4):543-56.

41. Korzycki M, Shaw L. Left behind in the return-to-work journey: consumer insights for policy change and practice strategies. Work. 2008;30(3):277-87.

42. Frank JW, Brooker AS, DeMaio SE, Kerr MS, Maetzel A, Shannon HS, et al. Disability resulting from occupational low back pain, part II: what do we know about secondary prevention?: a review of the scientific evidence on prevention after disability begins. Spine. 1996;21(24):2918-29.

43. Carroll LJ, Cassidy JD, Cote P. The role of pain coping strategies in prognosis after whiplash injury: passive coping predicts slowed recovery. Pain. 2006;124(1-2):18-26.

44. Allen D, Shore L, Griffeth R. The role of perceived organizational support and supportive human resource practices in the turnover process. J Manage. 2003;29(1):99118.

45. Holland J. Making vocational choices: a theory of vocational personalities and work environments. Odessa (FL): Psychological Assessment Resources; 1997.

46. Pransky G, Benjamin K, Hill-Fotouhi C, Himmelstein J, Fletcher KE, Katz JN, Johnson WG. Outcomes in workrelated upper extremity and low back injuries: results of a retrospective study. Am J Ind Med. 2000;37(4):400-9.

47. Franche RL, Krause N. Readiness for return to work following injury or illness: conceptualizing the interpersonal impact of health care, workplace, and insurance factors. J Occup Rehabil. 2002;12(4):233-56.

48. Blitz CL, Mechanic D. Facilitators and barriers to employment among individuals with psychiatric disabilities: a job coach perspective. Work. 2006;26(4):407-19.

Received for publication: 12 October 2009 